\title{
The Use of GIS in Urban Planning in Irbid City
}

\author{
Osameh Al Kassawneh \\ Department of Architecture, Faculty of Engineering, Philadelphia University, Philadelphia, USA \\ Email: okassawneh@philadelphia.edu.jo
}

Received 3 June 2015; accepted 25 August 2015; published 28 August 2015

Copyright @ 2015 by author and Scientific Research Publishing Inc.

This work is licensed under the Creative Commons Attribution International License (CC BY). http://creativecommons.org/licenses/by/4.0/

(c) () Open Access

\begin{abstract}
The GIS is one of advanced scientific means through which you can complete the planning in a realistic, accurate and effective way. By using GIS we are able to analyze the places and zones and couture lines for services. Therefore, the finance and time savings that might be supplied to Irbid Municipality were preparing millions in addition to large accuracy in the data presented.
\end{abstract}

\section{Keywords}

\section{Component, Formatting, Style, Styling, Insert}

\section{Introduction}

Jordan state tow targets first to pring technology in Jordan the second to use this software in deferent departments in Jordan.

The geographic information systems constitute the essence in many of the tasks and analyses and the most important are those that are performed by engineers, urban planning and transportation planners. In this paper, I will present an exploratory study to illustrate the links between organic GIS and urban planning, organization and analysis of the situation of public transport and the rest of the aspects of the infrastructure.

GIS applications have been the work of these seven arias that make up the city of Irbid and will discuss the situation of urban planning and breadth of business sectors random imposing themselves from the reality of the situation. It also will discuss the problems of planning and public transport.

That was noticeable that the threads derived from these different regions appeared to be of a special nature of urban confusion and random.

With respect to the heart of the research, this paper describes specific applications of GIS functions used in the planning and analysis of urban places' distortions in the urban fabric of the city of Irbid.

The ability of this program and its efficiency are measured by the accuracy and integrity of the data that feed 
them; we can notes that the threads derived from within these different regions with special nature of urban confusion and random organization (Figure 1 shows compilation of different layers [1]). All planes and sheets in relating departments are inaccurate.

\section{Information Systems Use in the Analysis of Urban Planning}

It is clear that urban planning in Irbid Municipality and since a long period of time, the analytical tools used in the assessment of the current situation compared with the current situation and past time periods and demographic changes that occurred to the city of Irbid and the expected future growth of the city of Irbid and the surrounding areas.

As the urban planning and for a long time also has other ways of adapting concepts and problem in all fields of study, such as the urban fabric of residential spaces.

Examples include that we have studied in Irbid Municipality and apply it to the conclusion of the broad population statistics and surveying data using .an classical method in the analysis of urban planning, land use planning, including residential and analysis of urban planning:

Methods and models of urbanization, and the definition of standards and the general parameters.

And methods of classification uses the ground within urban areas and which do not give the flexibility needed to help solve the problems of planning in this domain.

The blades lasting between urban planning and analysis of things were elusive and difficult for it to enter. Programs while geographic information systems in the field of planning. Where identified the capabilities of GIS software GIS on the analysis of objects and blocks and blanks spatial, and ownership of this information is available, and relationships every one each other. and when analyzing the planners of the past and found that the possibilities offered by the use of these programs are very large, and then if possible used to study the future and provide planning requirements as appropriate for the city's status.

Allows us to Lena scenarios appropriate to the operations of urbanization and provide us with the help of the task to make decisions properly oriented to the future.

The plan, however, is more than just paper models. While GIS is a digital databases linked to a specific geographic spatial locations.

Rather, the geographic information systems has become one of the important components of activities applicable in the current layout, where deals planners with a lot of institutions and the relevant departments in the field of service sectors such as Foundation water and electricity companies and telecommunications and public security, health and many other sectors (Figure 2 shows the places of containers presence and distribution of

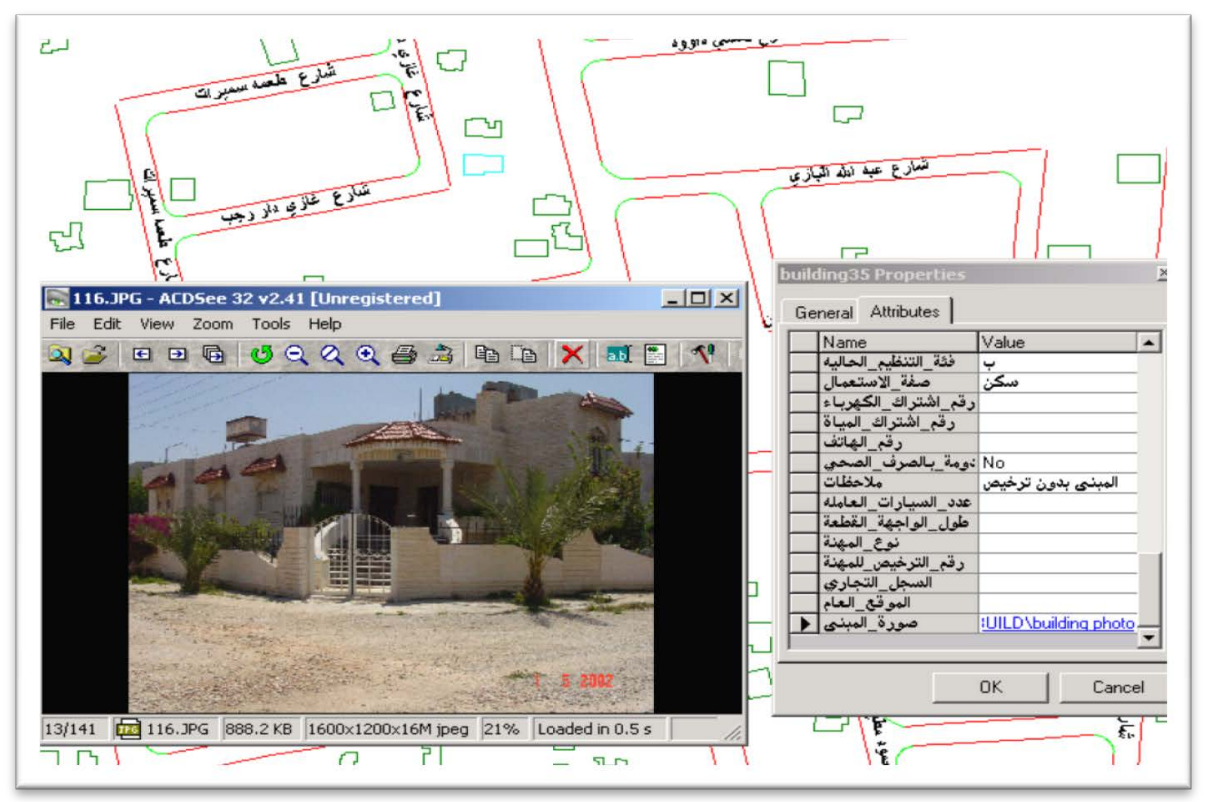

Figure 1. Estimation of taxes using the GIS information. 


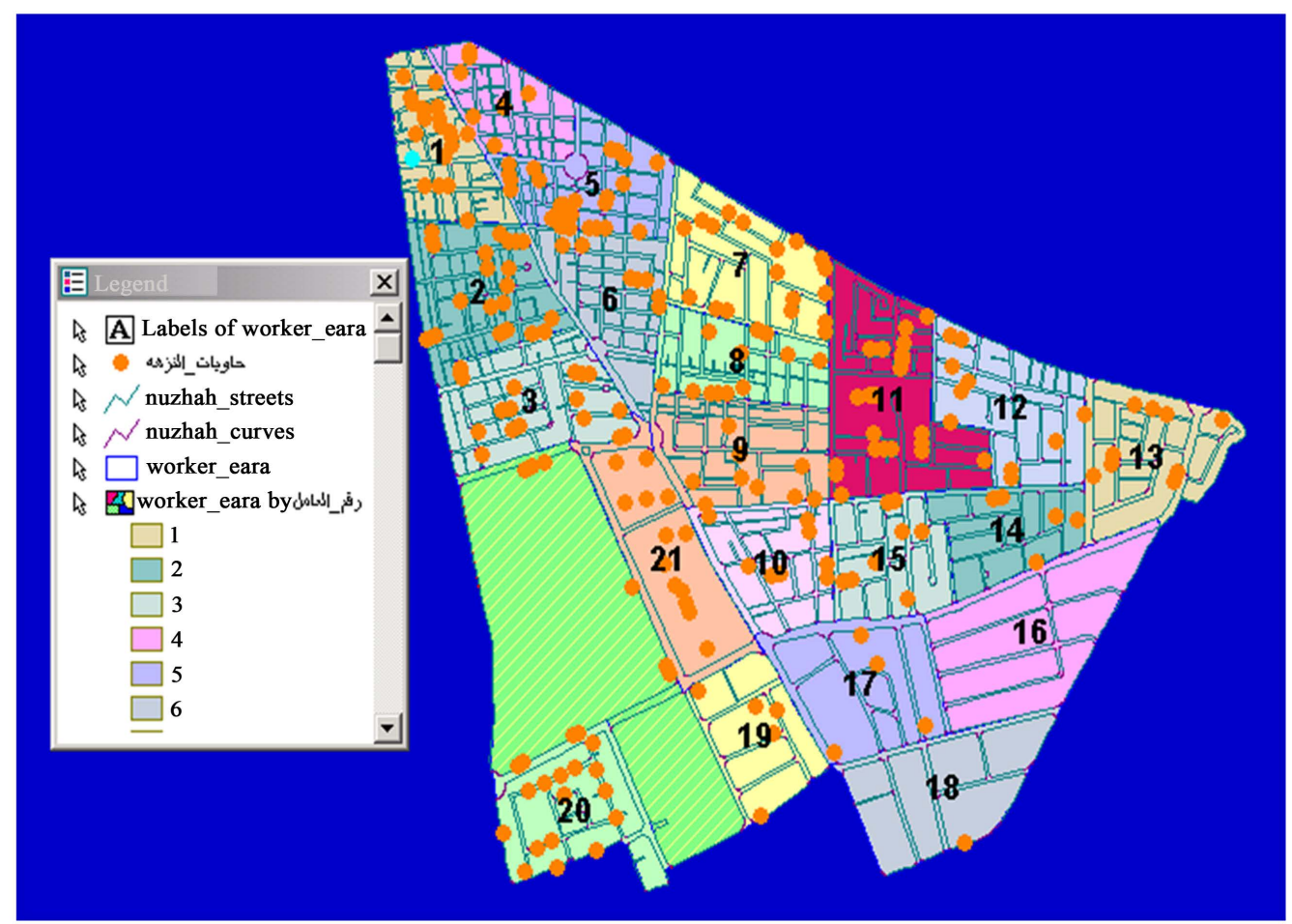

Figure 2. Places containers presence and distribution of cleaners areas.

cleaners areas [1]), reflecting problems of urban and regional complicate planning process an successful solution was instrumental in shaping the behavioral pattern of the society, which also feature a rational adaptive strategies to draw between the place and human. Here you can discuss the degree of awareness of the rational in the planning process and the viability of rational model. In any case, the phenomenon of the increasing use of GIS program after the disease has a significant drop in the cost of their operation.

Scheme illustrates the ability of software to give the population data needed for the scheme and the ability to take the appropriate decision.

Where the image shows an area of the house and piece and the provisions of regulation and form of construction and the number of family members and accurate estimation of the value of the home for the purposes of tax collection.

In a different type of contexts shows that GIS will be an important component in the process of urban planning in research and practice.

As long as the GIS, in the nature of the organization is a group of concepts, methods and techniques used in the planning process, it is also part of a wider process of rational take on the Supreme province alone but the whole country as a sample study

In any case that a GIS can contribute in determining the point of view broader planning as an organization and processing of information to provide us with the outputs of minutes if not very accurate, if it is used wisely, that the ability to analyze various activities clearly and explicitly provides service to all segments of the public in the city of Irbid. I have had years of the nineties and features that were considered in the information revolution as a period of significant information "design collective."

That any technical design processes and policy to facilitate social interaction and start talking in a bid collective goal. In this context, the Internet and the integration of GIS software information systems, GIS and other models have become important sectors really into the discussion into the collective determination of the city through the embodiment of social and environmental needs.

In this brief presentation we will focus on the use and transfer of ownership of the land are two axes of the key elements in urban planning.

Where the program will help GIS system to adjust and control the use and transfer of land holdings so that is consistent with the policies set out within the totalitarian planning and there are a large number of areas that are 
being the change and transfer of land-use and retail properties, which constitutes a major obstacle in the field of urban planning

The use of information systems GIS in planning, including the attributes of the forms of analysis makes the task significantly easier and works very efficiently. Here we can summarize places overlap and links between GIS and Urban Analysis and Infrastructure in the following points:

1) Spatial planning of urban and improve urban areas between populations.

2) Use of GIS in public transport planning and policy development for the future.

3) Transfer and discharge and solid waste treatment.

4) Street lighting and locations feeding stations (distribution stations).

5) Places sewer lines and treatment plants.

6) Points and the whereabouts of environmental problems.

7) Places and types of distribution services in the areas of high population density.

Began by urban planning program GIS rapid deployment in all parts of the world and of which Jordan, where it became urban planners now have the possibility of greater access to the use of this technique are widely available and inexpensive somewhat.

\section{The Use of Geographic Information Systems Affect Urban Planning in Four Axis}

The first axis - the provision of information and data which is necessary to the success of the work planned.

The second axis - increasing field surveys, which used to take a lot time in the operation of the scheme.

The third axis - the embodiment of the mistakes that can be located where the outline of the program through the provision of such notice, thereby determining the distances between the points of services.

The fourth axis - ease of connectivity between reality and imagination planned through the embodiment of the layers and show it in that one.

Greater Irbid Municipality seeks the implementation of this project is to create an integrated scheme for the city that includes all the elements and the data handled by the municipality to create a comprehensive database linked with pictures, maps and various data for various sectors in the city.

For example, if one application of information systems GIS most commonly used in the field of electrical services where possible to locate lines networks, low voltage and high voltage websites including columns and units luminescent which facilitates the operation of the scheme to target a specific area in the development and expansion of urban sprawl Urban where is the proverbial other process waste collection and regulate the movement of compressors machine and cleaners and gathering places containers and their suitability for the neighborhood, and this in itself works a pivotal role in preserving the environment.

\section{Analysis of the Reality of Urban Planning in the Province of North through GIS}

The government of Jordan dividing into three regions and to facilitate the work of urban planners and building policies based on decentralization in the local administration and the purpose of the distribution of financial allocations between the three regions (Figure 3), namely:

- Province of North

- Central Region

- South Region

And we will study the north and the province of this study include the city of Irbid and the surrounding villages from all sides, they called it together Greater Irbid Municipality (Figure 4 shows the north districts [2]) and the planned facility demonstrates that through GIS software used in Irbid Municipality.

And through the GIS software for the census was to determine population densities that are distributed across their regularly from the city for this purpose and possible action graph.

Annex of the transfer of data from the software information systems to the Excel software to give the chart to determine the desired target and places these graphs statistical been determined that the area of the city of Irbid is densely populated and attic were determined number

Population compared with the default ratio of population known increase during the next ten years, which would be nearly two million people, this FAQ is negative indicators encountered in the process of urban planning as if remained the case as far as the actual situation and there are significant challenges in its path. Figure 5 and Figure 6 show the distribution of north zone population according to [3] Department of statistics 2002.

Province of North/study and analysis 


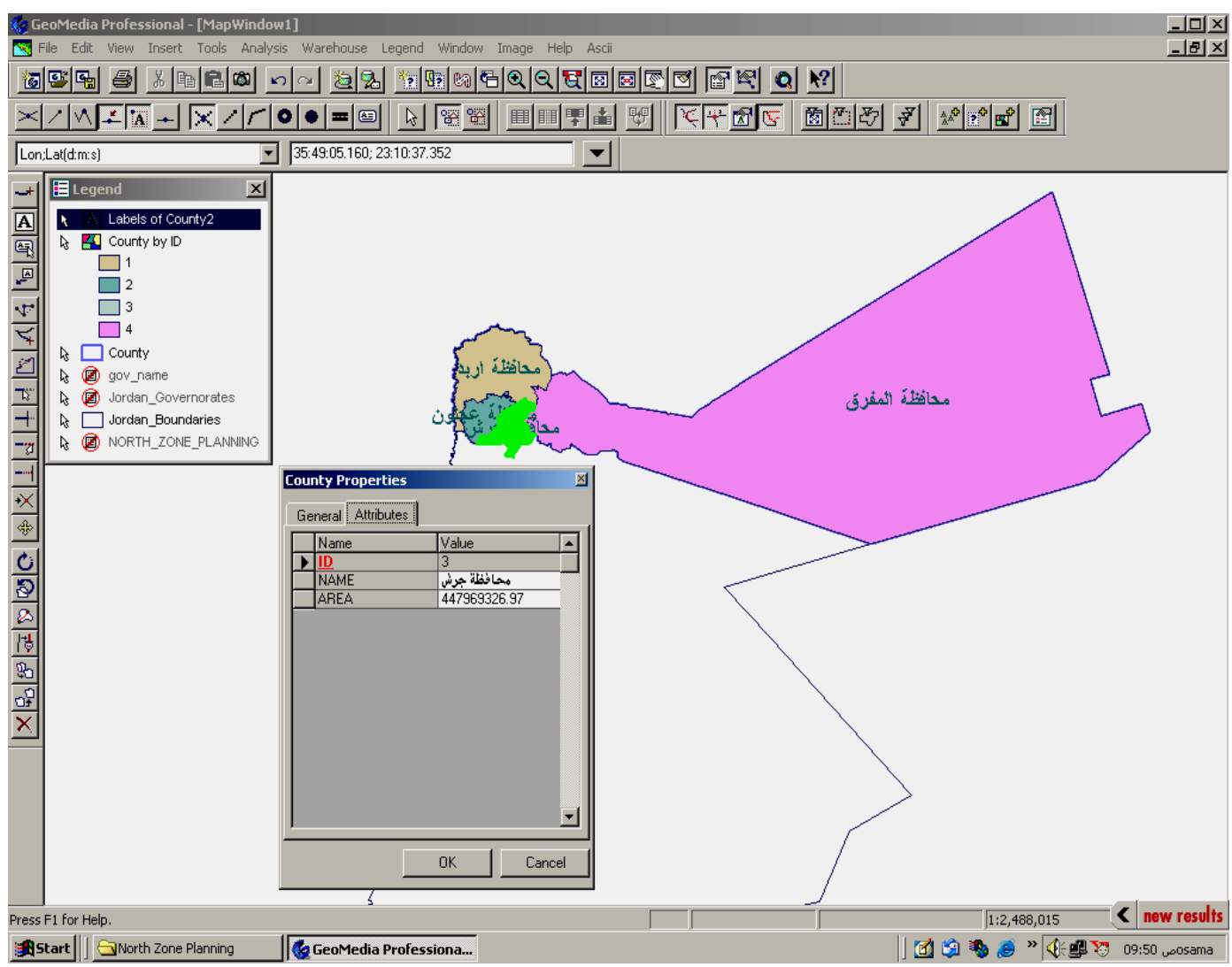

Figure 3. Scheme shows the accuracy of the administrative border of the province of North through GIS program.

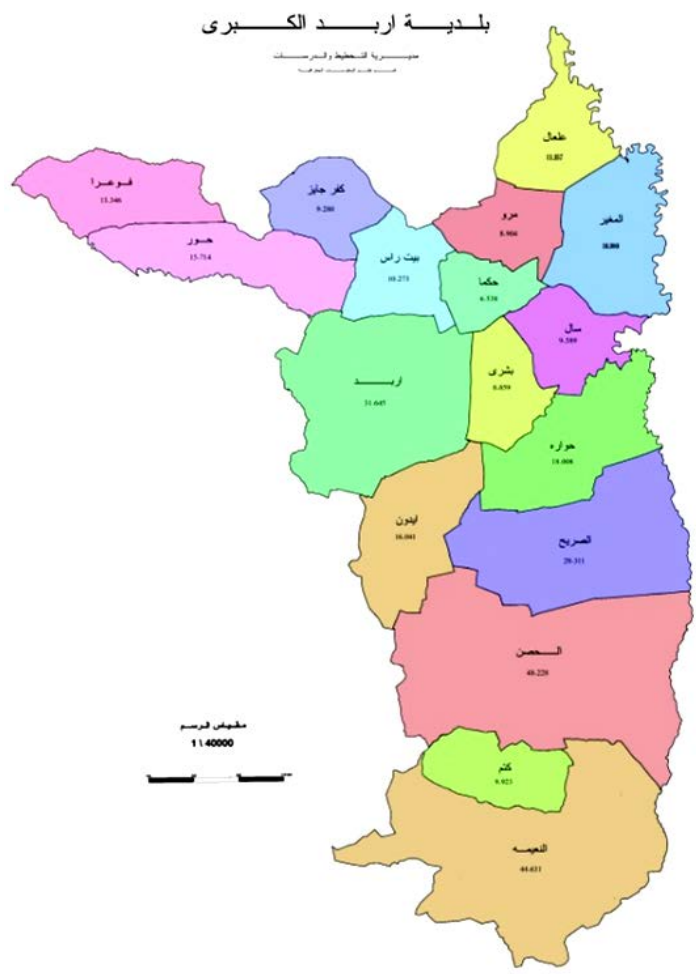

Figure 4. Scheme Greater Irbid Municipality after the merger in 2001. 


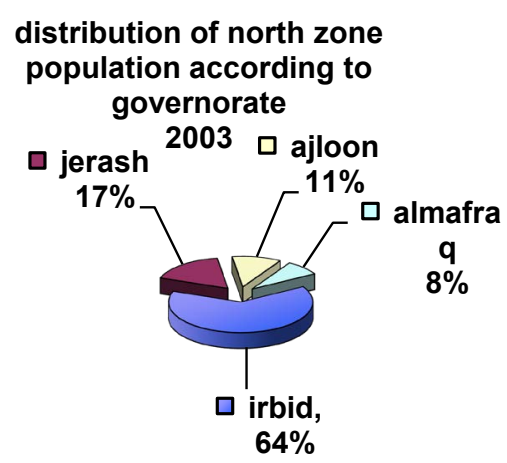

Figure 5. Graph shows the percentage distribution of the population showing the number of residents of the northern region during the period of ten years from the year 1994 to the year 2003. Ref/The documentation of GIS department project 2000-2004.

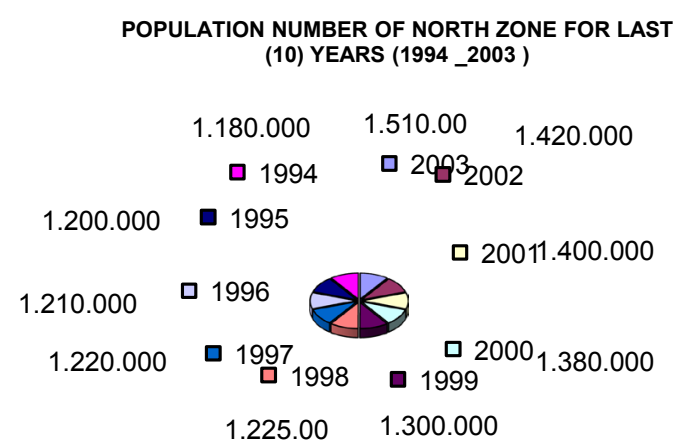

Figure 6. Graph shows the percentage distribution of the population in the provinces of North statistical graphs showing the number of residents of the northern region during the period of ten years from the year 1994 to the year 2003 [3] Department of statistics 2002.

And is the province contains the four provinces are:

- Irbid Governorate

- Mafraq Governorate

- Jerash Governorate

- Ajloun Governorate

Irbid Governorate and has an area of approximately $1573.11 \mathrm{sq} \cdot \mathrm{km}$.

The actual status in the zone:

Through what turned out to download all the cadastral layers show that the style of random and there is not any solutions or treatments to face the future and that the trend is toward expansion of urban farmland eastern regions most fertile and not on the western regions the most rugged and low where bad agriculture.

The GIS program gave a full explanation of the rankings for the administrative city of Irbid, but all Irbid Governorate so that it became possible to identify the area's most suitable prohibitionist interfaces for services or where urbanization without stirring an environmental problems as we will see in the area Eidon.

\section{Areas of Greater Irbid Municipality}

In August of 2001 (Figure 4), the government merged municipalities Irbid and around the village by seventeen and that they constitute a burden on the planning process and especially the multiplicity of types and the provisions of regulation in areas interfaces making it one of the aspects of the provisions of a residential street and the other side, the provisions of these commercial and housing area have been identified with high accuracy through a program of geographic information systems and the example is Prince Hassan Street between the areas of Irbid and Edon. Figure 4 shows scheme Greater Irbid Municipality after the merger in 2001 [2] Ministry of municipality affaires. 
From this graph can be a statement more areas that require priority for intervention Urban them to provide the necessary services, including health services, educational and commercial where it turns out that most of the population of the city of Irbid they make a purchase widgets from the city center any so-called zone of the old center Alhisbeh and this is an addition to the movement mobility of staff to their duty stations traffic jams at times exceed the morning rush hour and evening. Figure 7 and Figure 8 show distribution of the population in the areas of Greater Irbid Municipality [1]. The documentation of GIS department project 2000-2004.

The significant expansion in the use of software packages, GIS has the body of obstacles that may be encountered in the field of planning as the Mini prescribed by the program almost give the planned quality solutions putative and how to access them on the ground as a player the central role in reaching the shape design better as the ease of call data required by the scheme to help find alternatives to those solutions.

\section{Analysis of Urban Planner for the City of Irbid}

The urban planning has a long history using analysis tools realized goals incomplete and inappropriate in some cases either at the present time it has become the situation more accurately and appropriately in most cases and

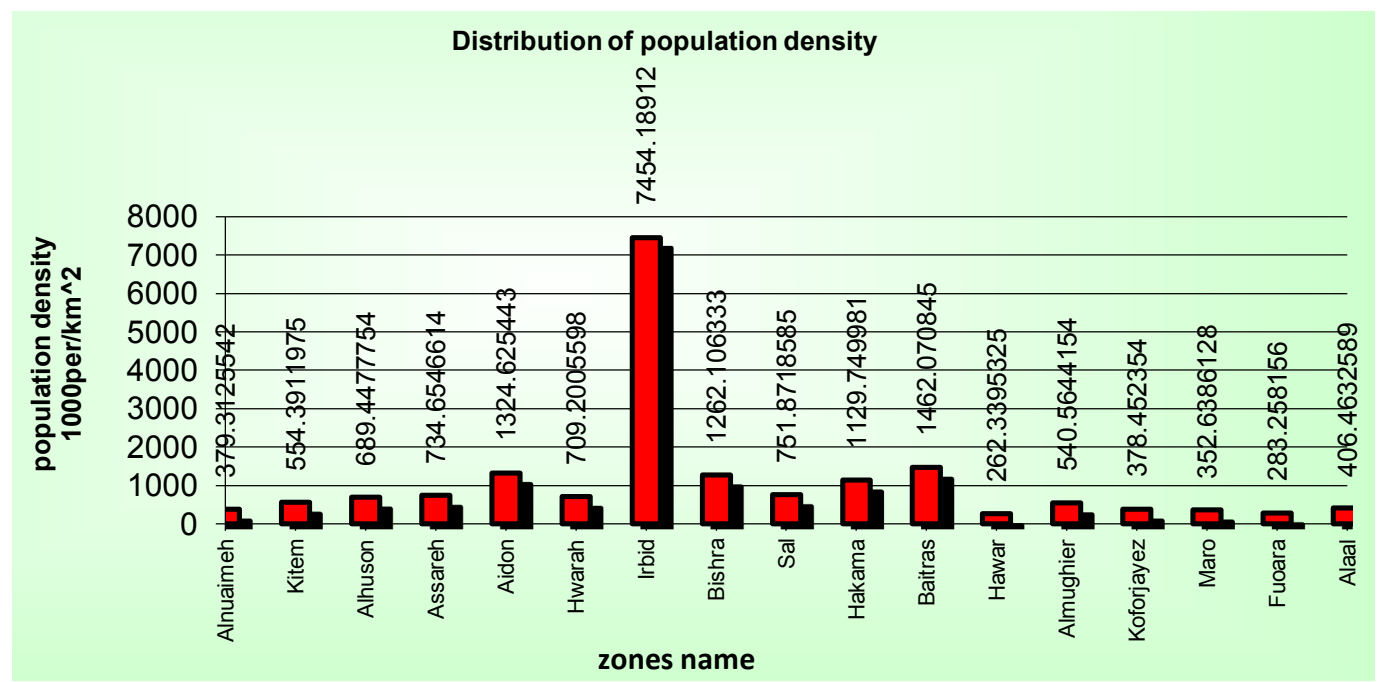

Figure 7. Distribution of the population in the areas of Greater Irbid Municipality. Ref/The documentation of GIS department project 2000-2004.

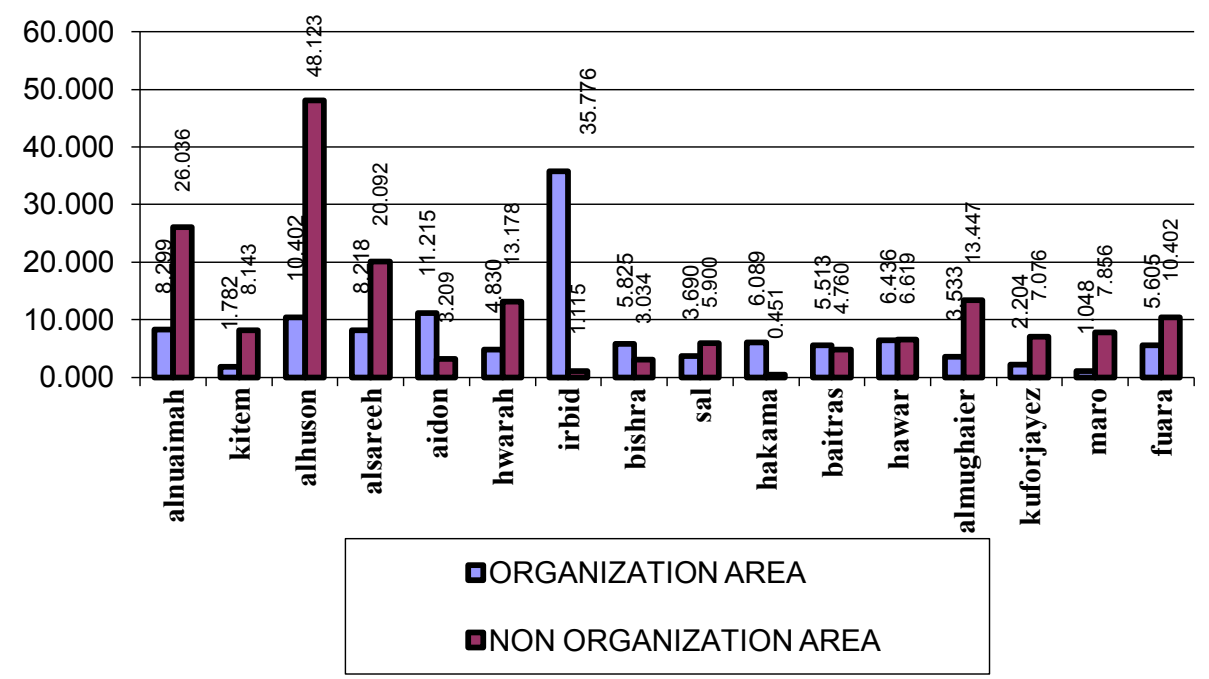

Figure 8. Distributed areas and areas of the organization within the Greater Irbid Municipality. Ref/The documentation of GIS department project 2000-2004. 
for all regions as the combination of multiple layers such as plates territory and planned structural organization with modern satellite image-resolution $50 \mathrm{~cm}$ gave us all possibilities to see actually correct all data on population and contour lines, and many other data upon which the main themes of the scheme to urban areas and all of them targeted for the study (Figure 9 shows Greater Irbid Municipality before the merger in 2001 [4]).

From these statistics we can see areas that can conduct studies where the quality of the projects that can be established at the present time and the development of future plans This makes it clear that the city of Irbid full area of organization and cannot establish a state projects with the exception of some areas of urban expansion, but can determine the quality of housing we might have to suit some groups that are not currently available in the city of Irbid, a group of buildings with a special classification of any establishment Villas roles only, without excesses by some to set up multiple buildings roles. Figure 10 shows the extension of Irbid zone in different years [2].

Without any regulatory controls where targeted agricultural areas in the city and is part of the eastern plains of the western part of the city, which clearly shows the difficulty and the complexity of the region and the low level of agriculture and where these plains, which was one day a basket of wheat to Rome, which are called plains Horan.

The GIS has given us the ability to identify areas of large distortions in our scheme (Figure 11 [2]) of regional national show where the following matters:

1) That urbanization in the city of Irbid heading toward the eastern region classified as a symbol in agriculture.

2) Random craft areas between many areas of the city, which cannot be controlled in the absence of the master plan expected to be completed properly.

3) High rate of environmental pollution in different regions.

4) The possibility of proper management to manage the demand for electricity, water and other services.

5) Systems development and transfer of solid waste that drains energy in the merged municipalities.

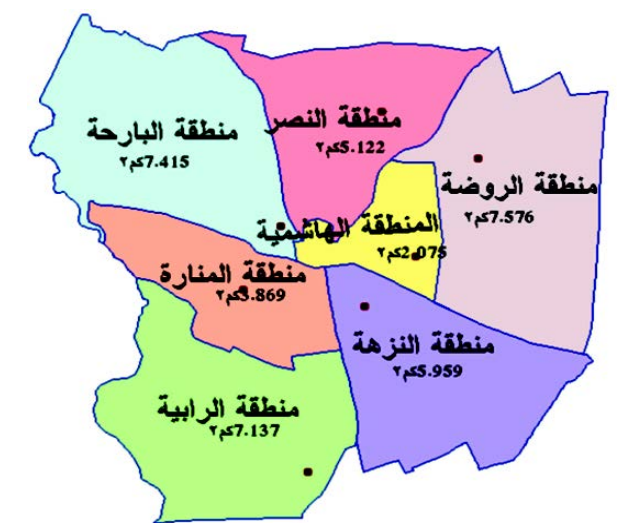

Figure 9. Scheme Greater Irbid Municipality before the merger in 2001.

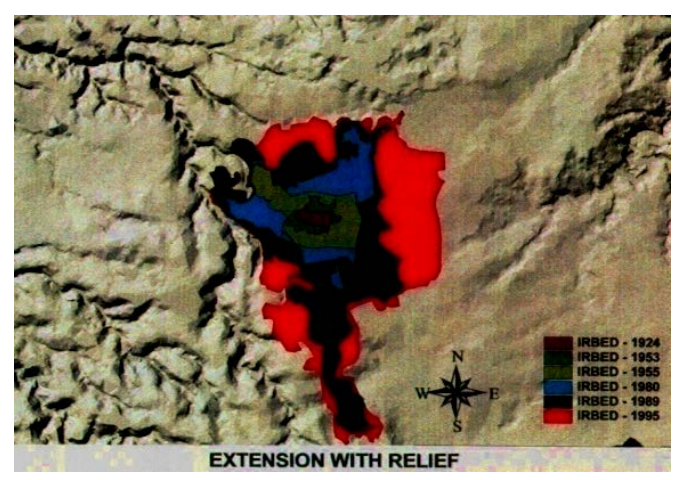

Figure 10. The limits of the city of Irbid through the satellite image and show the natural terrain and areas of flat also shows time periods successive expansion of the city coupled with the time period and the reasons for this expansion also shows the wrong direction, in the direction of urbanization, which is, in fact, the expansion of a random city. 


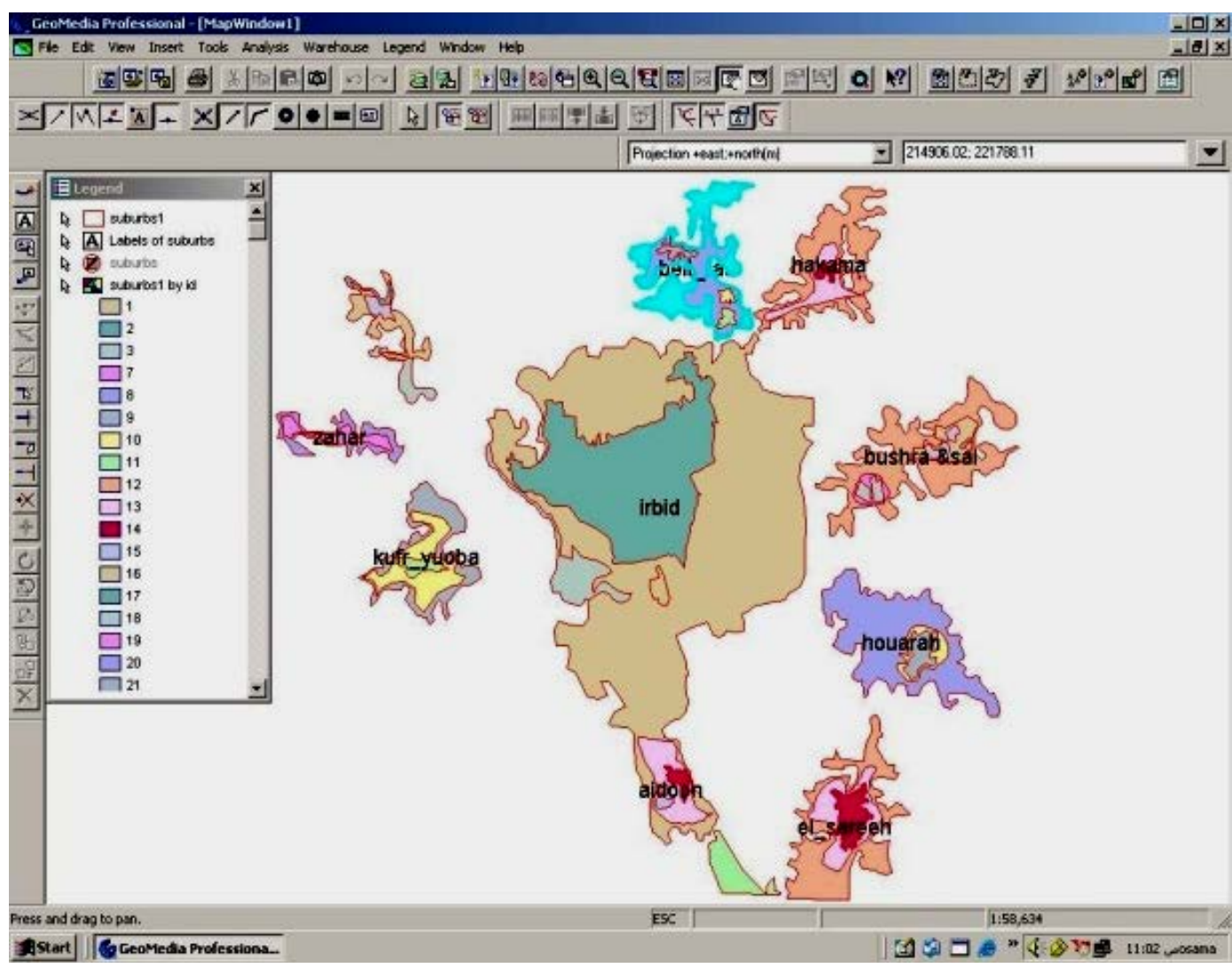

Figure 11. Irbid City and its neighborhood.

6) Management control over public transport lines and the use of intelligent control systems.

7) The Used Scheme of Land in the Greater Irbid Municipality

I've been the ratification of the first master plan for the city of Irbid in 1970 of the last century under the administration and supervision of the Ministry off municipalities and was based holding amendments periodic attic directly making this chart paper planner Pollack concept for the large number attic of lines and notes dated on Council resolutions organization this makes the top and the ability of surveyors to violate it easy and possible to do so, but he and after it has been developing land use planner and postings on the GIS software has become easy to handle things in all the sites with the Director of Planning and Director of the organization, as well as mayor also, the process of extracting the desired planned target of logic is made easy and takes only minutes.

The embodiment of fact situation and linking it with other forms of study with a view minutes makes the possibility of linkage between the results and the analysis is a high level of success schematic.

The GIS software may work force planned by the strong link between the blocks populated with blanks space and thus identified the quality of these spaces and it's needed. Figure 12 shows center of Irbid City and transportation lines [1].

The planning is in fact more than just forms and models for this, the software of geographic information systems, which give the necessary information for voids interfaces that form the database it so it has played by this software a big role in planning activities around the world and which we sanction it and which gives a lot of scenarios free of complexity that contribute effectively to clarify the vision of the scheme and to the decisionmaker alike.

Scheme illustrates the uses of land in the south-western region of the city of Irbid (zone Zabda) And this scheme is available to all regions of the Greater Irbid Municipality, without exception, and can show the extent of randomness in the selection of regulatory provisions of the various regions we can see that the classification provisions of $\mathrm{a}, \mathrm{b}$ are the most, bringing much of the price of the land, which has become difficult to obtain on the citizens of the middle-income and in the limited time that was tightly requires work areas for $\mathrm{c}, \mathrm{d}$ (Figure 13 shows land use plan [1]) space-least-cost and least this possibility was not available before the use of GIS soft- 


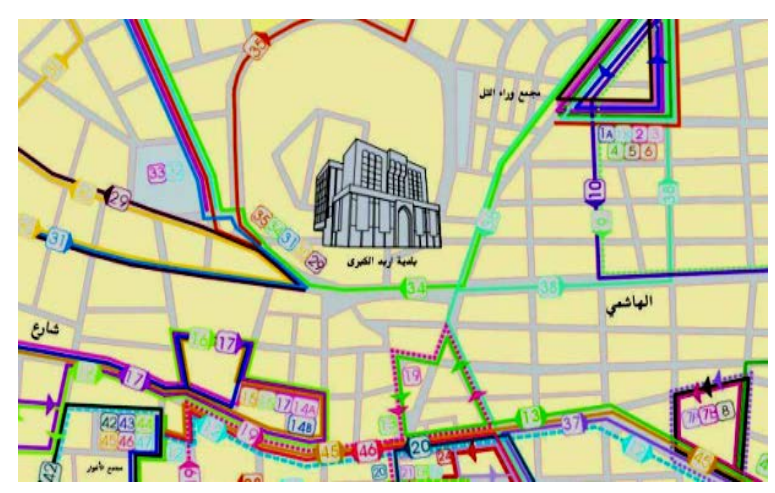

Figure 12. Center of Irbid City and transportation lines.

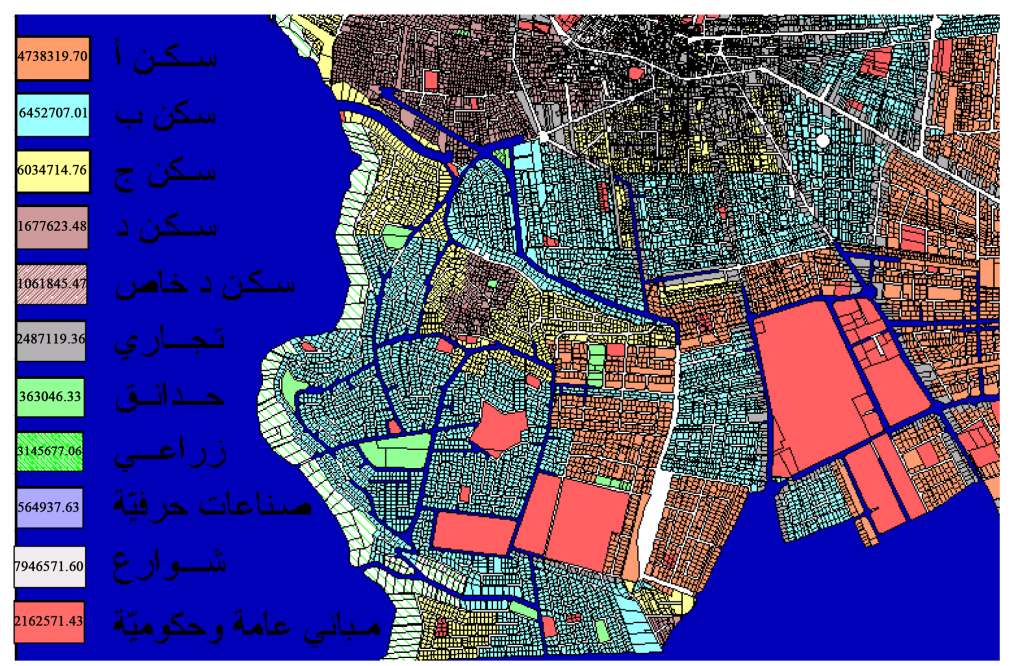

Figure 13. Scheme illustrates the uses of land in the south-western region Zabda.

ware and without doubt has entered this code in the heart of the work and activities in urban field in Greater Irbid Municipality.

The GIS software and its tools and the different organization of the data and its processing has proven superior ability on the speed of communication and team work between the analysis in planning projects undertaken by the competent authorities and all of these processors:

1) The targeted social categories for the study.

2) Economic analysis which gives the economic level of the target group for the study.

3) Analyzes indicate places where environmental pollution and the quality and impact and its proximity to the targeted areas.

4) Demographic studies show where reconstruction and nationalities of the resident population in the targeted areas .

5) Geological analyzes of the target area.

Scheme illustrates the limits of neighborhoods within a single area in the Greater Irbid Municipality (Beit Ras)

Have been completed scheme transport mines in the city of Irbid through the process of monitoring and follow-up of all the transmission lines within the city of Irbid and trends walk by and the result was that embodies the flaw in the path of public transport and charts extracted shows that a very large part of the city of Irbid is not serviced by means public transportation (Figure 14 shows scheme of public transport in the city of Irbid [1]) and has been determining the number of the inhabitants of those areas, and the study showed the need to restructure and regulate the transport sector in the city of Irbid note that this sector is private sector (Figure 15).

Increasing the cost of buying and running this software is relatively helps to circulate use and data exchange among competent authorities. Figure 16 shows scheme of public transport in the city of Irbid [1]. 


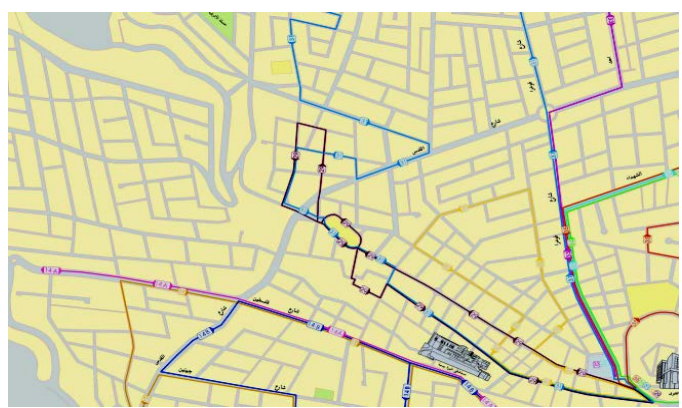

Figure 14. Scheme of public transport in the city of Irbid, as we are doing through the GIS software shows multiple lines for all areas of the city of Irbid, showing the distortions in the paths of the transportation lines.

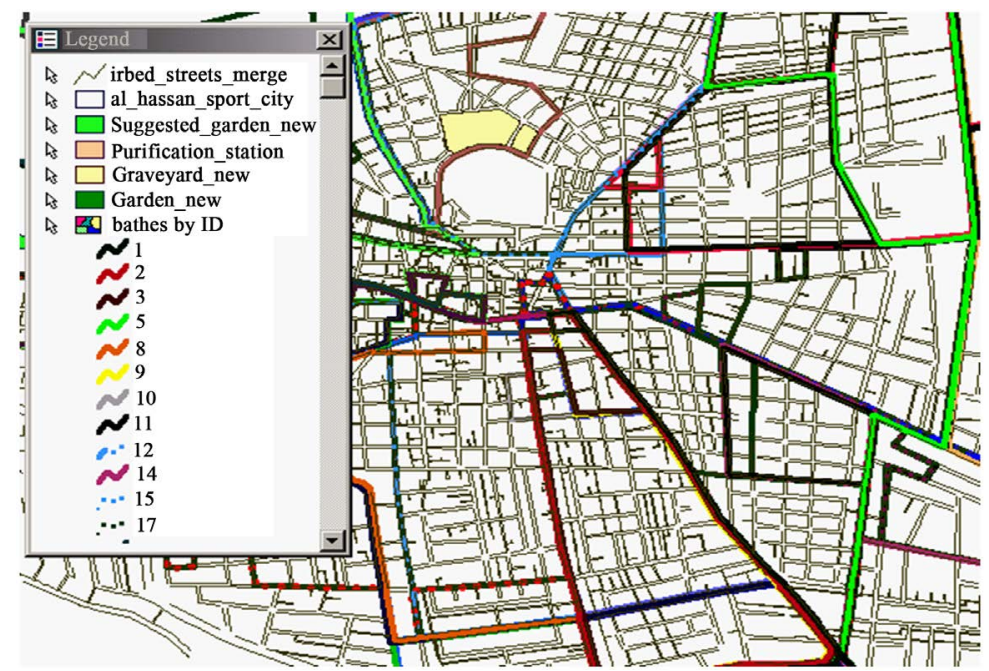

Figure 15. Scheme illustrates the ways and public transport lines in the center of the city of Irbid and the extent of overcrowding in these lines compounding crises traffic in the city center and this scheme has become a much easier task planned in the study of traffic problems and develop solutions to regulatory her.

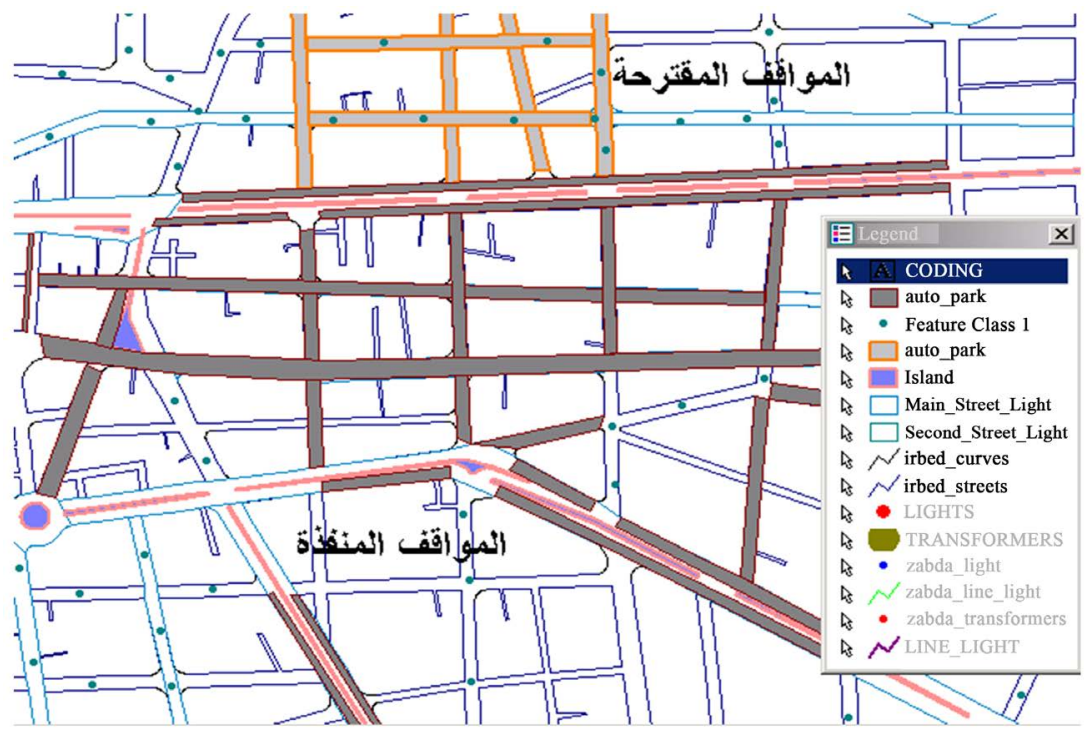

Figure 16. Scheme transport mines (suggesting parking streets in Irbid City). 
Through the opening of new streets and paths change means mobile public to become more streamlined and effective, which reduces the time period of movement within the areas of Greater Irbid.

Here we can discover the positive interdependence and interactions between GIS and analysis in urban planning:

1) Planned to improve the spatial urban through clarity in the data.

2) Analyzes to improve public transport scheme in terms of population density and the number of transport operating them and issued by the code.

3) The use of GIS software in the management of public transport at the city level.

Scheme shows the populated areas of the city of Irbid are not serviced by public transport, and this shows the extent of the suffering faced by the population in that region.

Scheme to organize the project parking Pay part of a project to solve the problem of traffic jams in the center of the city of Irbid where he helped reduce the number of cars coming into the city center by area merchants for more than $30 \%$ of the total cars in the region where the merchants come in their cars and parking it in nearby streets along any period of the day nearly twelve hours so that visitors do not find parking for their cars to shop in the area, but this project has stumbled after it runs for two months due to mismanagement by the company which working for operation and investment.

Figure 17 shows the areas that have been identified through software geographic information systems such as areas most polluted in the city of Irbid where we started the development of solutions to them within the plans of municipal and waiting for financial resources to resolve as diagram shows the main roads between towns and villages to the city of Irbid and from this scheme we could identify a need areas of new roads [1].

Scheme shows the streets of the city of Irbid and their names indicating the buildings that are located on these streets with all the data for these buildings, and images and the names of the owners and the number of inhabitants and the phone number where the use of such data in several purposes, the most important statement of the title to the house through a dial-up only Call center also benefited from the Department of Finance in the collection of tax and Almsagafat estimate this tax through these pictures where the value is calculated automatically by the software accompanying the GIS software (Figure 18 [4]), which facilitates a lot of effort and fuss in the disclosure on the ground and repeat it again.

This scheme is easy to put the pieces planners know the target of the study and what the measures it has been taken in the past, making it easier to open the streets and the establishment of new commercial centers within

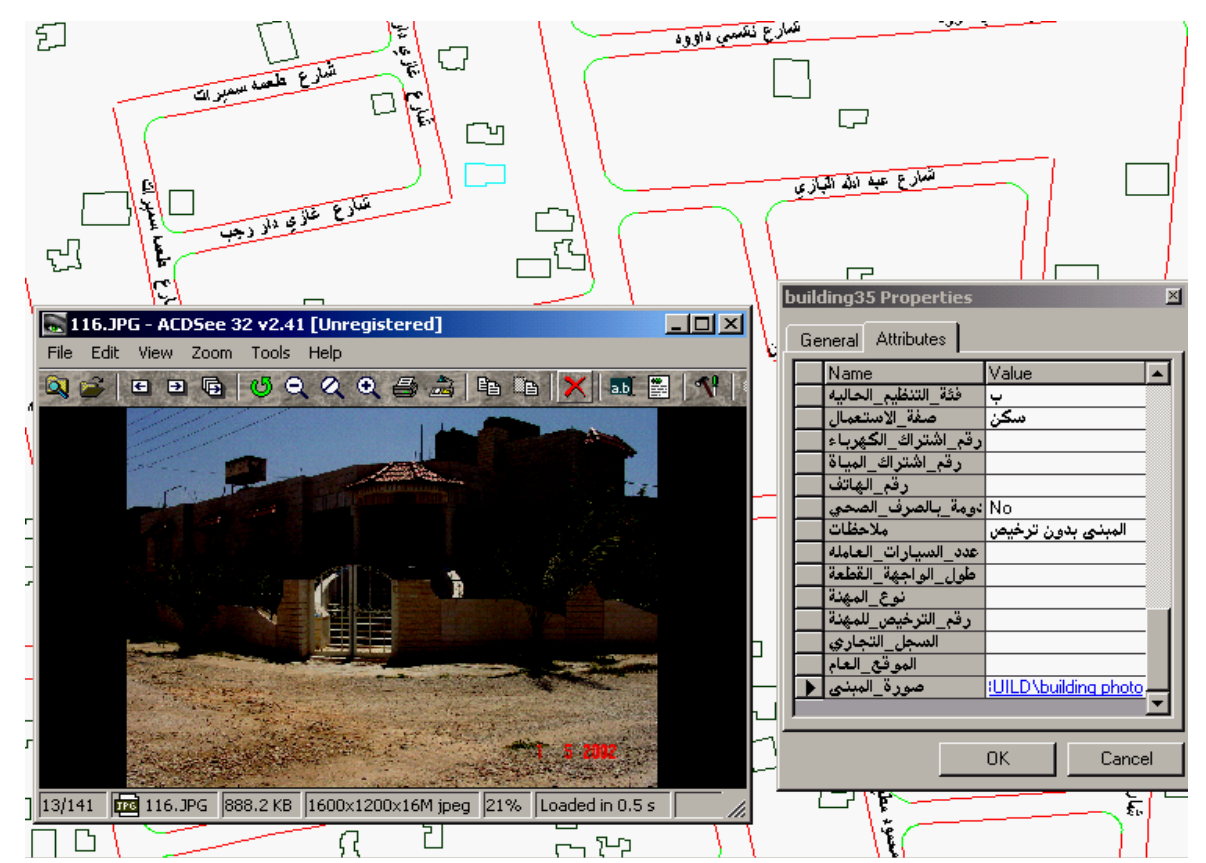

Figure 17. Scheme shows the streets of the city of Irbid and their names indicating the buildings. Ref/1 The documentation of GIS department project 2000-2004. 


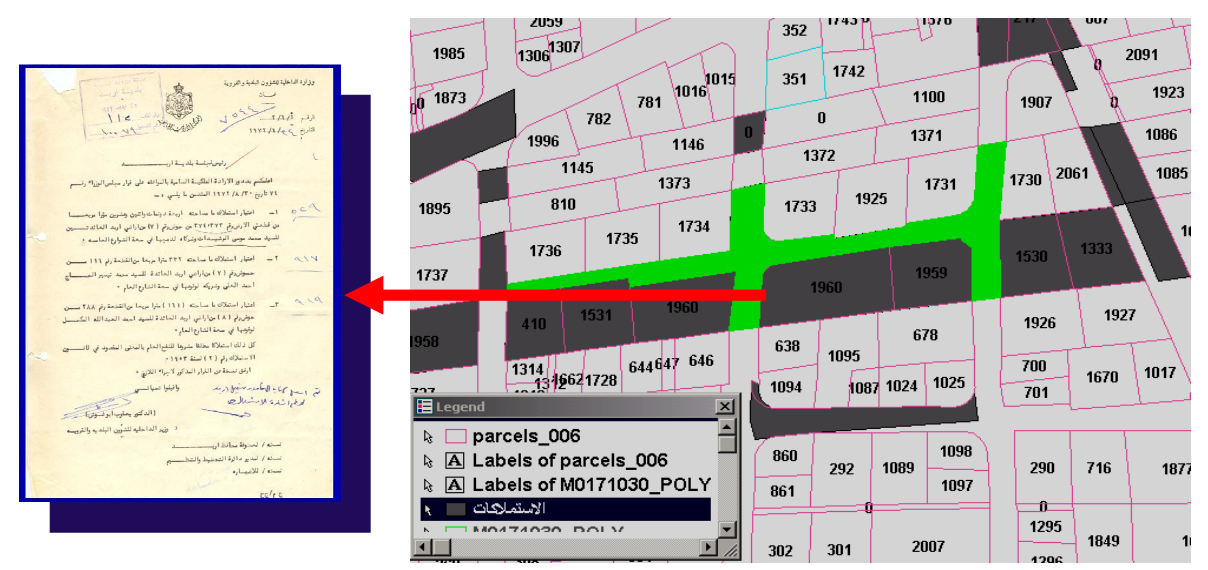

Figure 18. Scheme through GIS software shows pieces of land and leftover and the corresponding attached pictures for official referenda letter planned acquisition of the Supreme Council of the organization as released [1].

regions and determine the financial costs, as well as the establishment of schools within areas that lack them or be far from it.

The plate's territory and organization of paper available in the departments concerned are susceptible to damage or expansion and contraction, which makes taking the data reported is inaccurate and so we still suffer from a high rate of offsets in the pieces of land all over the Irbid and perhaps all over Jordan. Where were canceled this problem occurs when we founded the Department of geographic information systems in the Greater Irbid Municipality.

When we founded the Department of Geographic Information Systems in the Greater Irbid Municipality. This program had a big role in solving more problems if not all, where provided for the study of the infrastructure of data crisis, and here refer to the sewage project, which was supposed to benefit from a layer of land and contour lines with satellite images and determine elevations of the sewer lines and densities population and determine the capacity of these lines.

The ease of dealing with this software and extraction schemes or Statistics or displayed and studied has changed dramatically the style of planning in the municipality.

This region is also evident from the corrected satellite image and the area, which is located south of Aidon (Figure 19 [1]) on the road to Ajloun where there number block saws and stone, which launches a lot of fine dust in the air up to the houses that are located within the region and that the residents complained repeatedly of this problem, which still suffer from it until now, and the municipality has failed to solve this problem that established the Department of geographic information systems in the municipality and to identify possible areas for several options that can transfer these industries to it and waiting for a solution to the subject under financial allocations.

The availability of information in all areas simply means power, whether in the military field or area of civil as well as applies to the planning process if available data and information required and easily accessible and displayed and linked with other areas to make of the decision-maker and planned more power to reach to the decision and from then schematic style desired and appropriate and in the required speed.

One of the areas that have been studied and show where in the random distribution of buildings and roads and traffic intersections where an entrance area Aidon neighborhood zone Aleon.

It also demonstrates how to use the wrong valley s rain path due to lack of knowledge Planners residing in Amman (who are working in organization zones) to the nature of the region in order to avoid this problem.

As possible to take advantage of the data section of geographic information systems in the process of division that took place in this region where it was limited to the number of trees and buildings and places of existence for the purposes of compensation in land purchases planned very accurately, which allows us to work within the budgets allocated for the completion of work (how you see in Figure 20 [1]).

As has been the study of this region have been identified traffic and places that are a danger to pedestrians so that they can be processed by the possibilities available. 


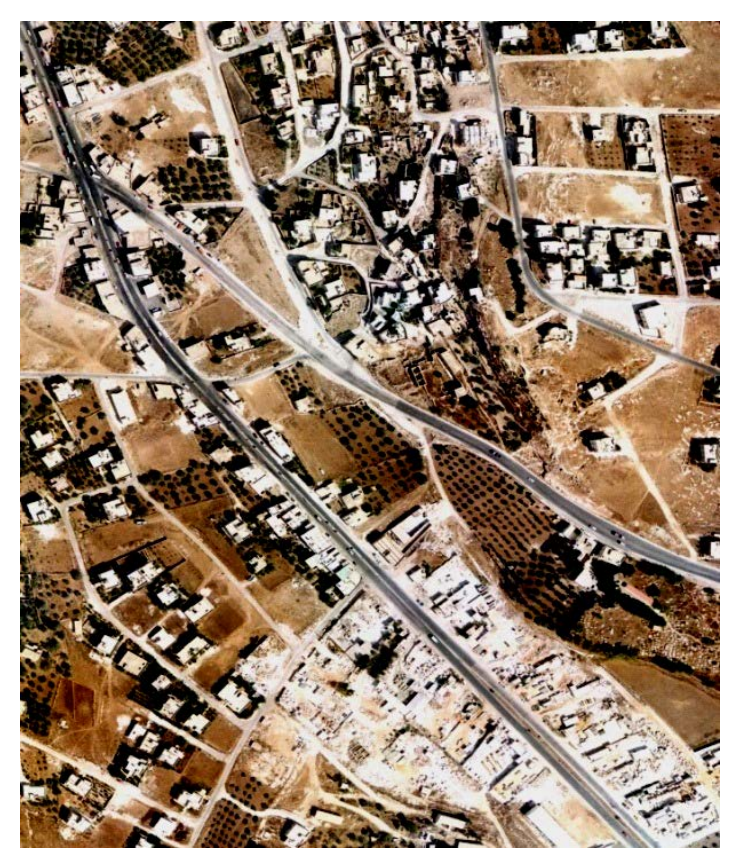

Figure 19. The corrected satellite image for Aidoun zone.

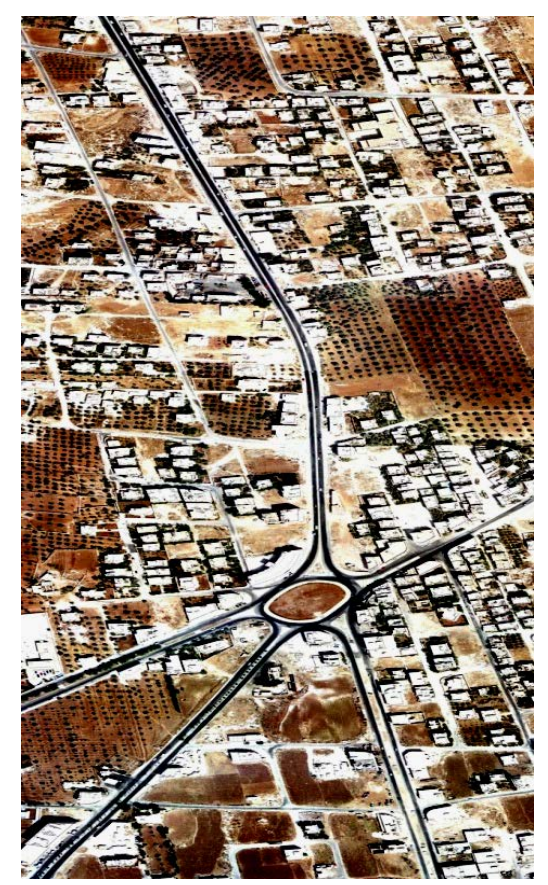

Figure 20. Satellite image shows how the distribution of residential blocks on farmland with secretion random and determine the quality of the appropriate classification for the target group in urban planning.

Another area of areas of the city of Irbid, between an area Bayada and Baitras (Figure 21 [1]) entrance of the city of Irbid North is the area has been studied through the software of geographic information systems for the provision of commercial services have been set up trade center for fruits and vegetables in it, which has helped to reduce the movement of people in the region and nearby areas of the city center shopping where they are in the process of shopping the old city center (Alhesbeh) in the past, which increases in congestion traffic. We can also watch spatial voids that can be handled by the area where the need can be expropriated from the statement of the part numbers involved and identify the names of the owners to make the process of acquisition. 


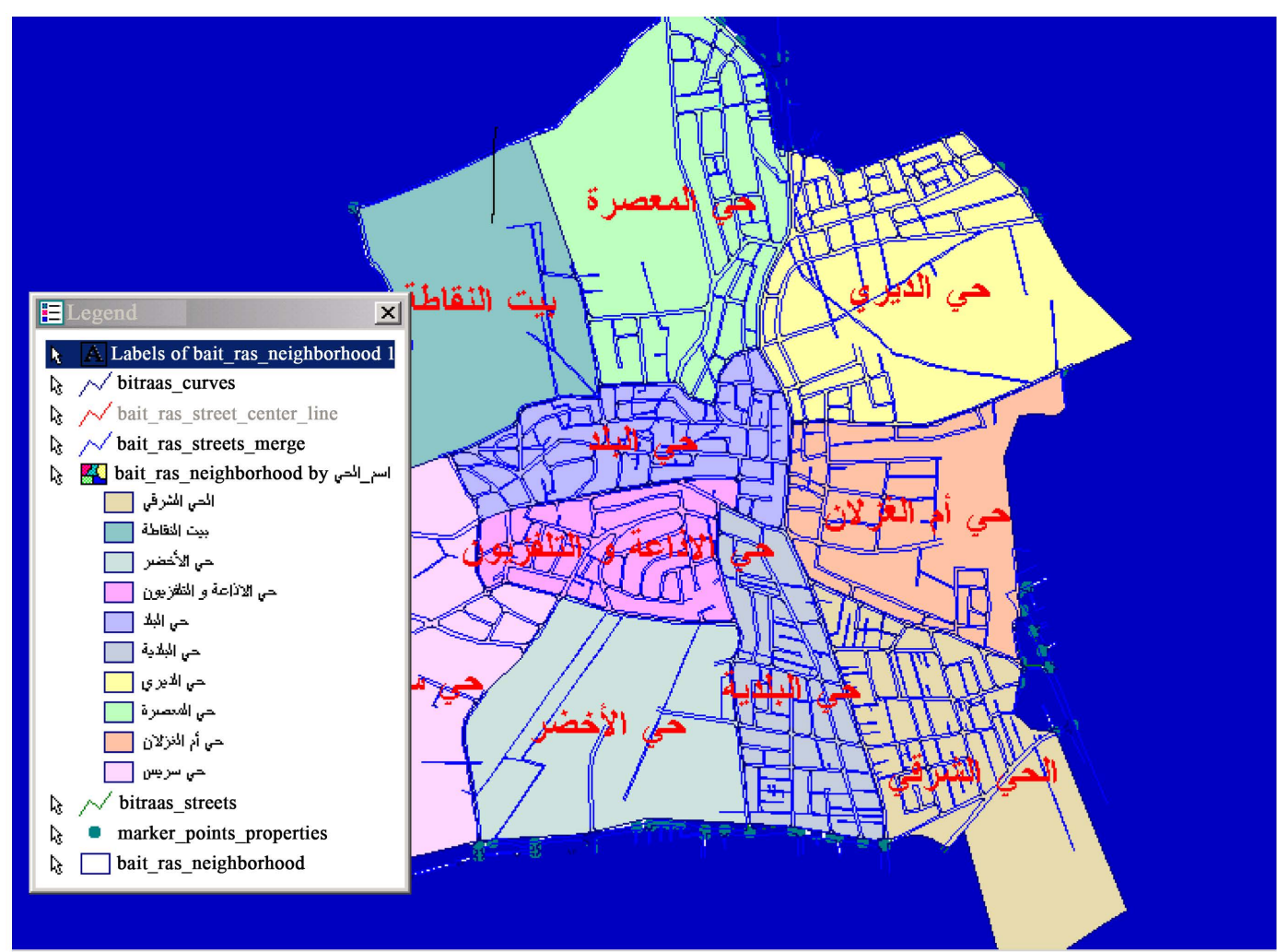

Figure 21. Scheme appears in one of the areas is the area of Beit Ras.

\section{Research Conclusions}

Through analyzing and studying this research, it shows that the desired success in the field of planning depends on the possibility of providing the necessary data and elements for the planners of all supplies and facilities necessary for the population to provide the appropriate environment of sustainability and social polarization to achieve the goal of utopia [5] [6] that everybody aspires to achieve in all the cities in the world.

So, we can make the conclusion of this research. We must define the term planning as the scientific method to achieve the goals through the means available to the highest efficiency from which we can determine the means available in the following items:

1) GIS is a major scientific means to provide the necessary data for the target area in terms of space and its geographical nature and proportions of inclination [7]. The results of drawn under the scanner light photosynthesize in royal geographic center could be in accurate.

2) The determination of these data will enable us to determine the material costs to complete the project properly and thus lead to the success of this project in all respects and the right time.

3) Know that all the data mentioned will enable us to identify problems that require resolution in each region by linking with other solutions in the areas adjacent to reach the urban plan homogenized and this is one of the main objectives pursued by planners [8].

4) Show where the contour lines and the distribution of population density and classification of social planes and the urgent needs and pollution resources and roads serve the zone; from that we can see the strong relation between planning and GIS.

5) Many countries are going to use GIS in urban planning and project management.

To make registration for many different sheets with images gives us a clear show in planning project.

\section{Acknowledgements}

I would like to thank Greater Irbid Municipality for supporting of this research also I would thank Philadelphia University represented in its president and engineering faculty dean. 


\section{References}

[1] The Documentation of GIS Department Project 2000-2004.

[2] Ministry of Municipality Affaires 2002-2003.

[3] Department of Statistics 2002 Irbid Municipality.

[4] Greater Irbid Municipality Annual Financial Report 2003.

[5] Anas, A., Arnott, R. and Small, K.A. (1998) Urban Spatial.

[6] Karimi, H.A. and Blais, J.A.R. (1996) Current and Future Directions in GIS. Computers, Environment and Urban Systems, 20, 85-97. http://dx.doi.org/10.1016/S0198-9715(96)00002-6

[7] Planning Association, 61, 438-457.

[8] Landis, J. and Zhang, M. (1998) The Second Generation of the California Urban Futures Model. Part 1: Model Logic and Theory. 